M. F. Carvalho - R. Ferreira Jorge • C. C. Pacheco •

P. De Marco - I. S. Henriques - A. Correia •

P. M. L. Castro

\title{
Long-term performance and microbial dynamics of an up-flow fixed bed reactor established for the biodegradation of fluorobenzene
}

\begin{abstract}
An up-flow fixed bed reactor (UFBR) was established to investigate the biodegradation of fluorobenzene (FB) under a number of operating conditions, which included variation in the concentration of FB in the feed stream (up to $180 \mathrm{mg} \mathrm{l}^{-1}$ ) and temporary suspension of feeding. Degradation of FB was followed for a period of 8 months under a continuous flow regime. During the operation of the UFBR, FB was never detected in the reactor effluent, being biodegraded by the microbial biofilm or adsorbed to the granular activated carbon (GAC). Biodegradation of $\mathrm{FB}$ was observed from the beginning of the reactor operation, and overall, it accounted for $50 \%$ of the total amount fed to the bioreactor. High organic loads of FB (210-260 $\mathrm{mg} \mathrm{d}^{-1} \mathrm{dm}^{-3}$ ) were found to affect the biological removal efficiency, possibly due to an inhibitory effect caused by the higher FB concentrations fed to the bioreactor (149-179 $\mathrm{mg} \mathrm{l}^{-1}$ ). When FB feeding was suspended for 1 month, biodegradation continued, indicating that the adsorbed FB became bioavailable. Biofilm bacterial dynamics were followed throughout the UFBR operation by denaturing gradient gel electrophoresis and plate-counting techniques, showing that a quite stable community was found in the bioreactor, and this was mainly attributed to the high selective pressure exerted by the presence of FB.
\end{abstract}

\author{
M. F. Carvalho · R. Ferreira Jorge · P. M. L. Castro $(\bowtie)$ \\ Escola Superior de Biotecnologia, \\ Universidade Católica Portuguesa, \\ Rua Dr. António Bernardino de Almeida, \\ 4200-072 Porto, Portugal \\ e-mail: plc@esb.ucp.pt \\ Tel.: +351-22-5580059 \\ Fax: +351-22-5090351 \\ C. C. Pacheco · P. De Marco \\ IBMC, Universidade do Porto, \\ Rua Campo Alegre, 823, \\ 4150-180 Porto, Portugal \\ I. S. Henriques · A. Correia \\ Departamento de Biologia, Universidade de Aveiro, \\ Campus Universitário de Santiago, \\ 3810-193 Aveiro, Portugal
}

\section{Introduction}

Haloaromatic compounds constitute an important group of pollutants that have been widely released into the environment as a result of their common use in industries and agriculture. Due to their useful properties and to the need of finding acceptable alternatives for many chloroaromatic pollutants, the use of fluoroaromatic compounds became more frequent in the last decades. The physicochemical characteristics of these compounds often make them highly recalcitrant pollutants, with low susceptibility to microbial degradation (Key et al. 1997). Nevertheless, the biodegradation of fluoroaromatics has been reported by several authors (Wunderwald et al. 1998; Song et al. 2000; Vargas et al. 2000). Very few studies are available on the degradation of fluorobenzene (FB), a recalcitrant fluoroaromatic compound. The potential sources of environmental release of this compound are related to its main use as a solvent in the pharmaceutical industry, as an insecticide, as a reagent for plastic and resin polymers production, and as a starting material for the industrial production of many fungicides and drugs (Banks et al. 1994; Freitas dos Santos et al. 1999). Our previous research on microbial degradation of FB resulted in the isolation of a bacterial consortium and, later, of a pure bacterial culture (designated as strain F11) capable of FB degradation when this was present as a single carbon and energy source (Carvalho et al. 2002; Carvalho et al. 2005).

Biofilm reactors are extensively used in environmental biotechnology and are generally considered as an effective process for the biological treatment of waters contaminated with organic pollutants (Armenante 1998; DeFilippi and Lupton 1998). Such reactor systems allow for the accumulation of high concentrations of active biomass, and when packed with a suitable matrix, organic matter may be removed through a combination of physical adsorption and biological transformation, constituting a good solution for the treatment of large effluent volumes containing low concentrations of pollutants and slowly biodegradable compounds. The removal of organic pollutants by immobilized microorganisms has been reported by several authors 
to be much more effective when compared to suspended bacteria (Heipieper et al. 1991; Lee et al. 1994; Shi et al. 1995; Abu-Salah et al. 1996). Due to its rough surface and highly porous structure, granular activated carbon (GAC) is a good attachment surface for biofilm development as well as an effective adsorption matrix for different compounds, also serving as a buffer against shock loads of toxic compounds (Abu-Salah et al. 1996; Khodadoust et al. 1997; Carvalho et al. 2001; Moteleb et al. 2002). Immobilized bacterial GAC reactors have been efficiently used for the treatment of several aromatic compounds (Feakin et al. 1995; Shi et al. 1995; Klecka et al. 1996).

In spite of biofilms constituting a fundamental component of immobilized bioreactors, little is known about the relationship between biofilm microbial dynamics and bioreactor operation. Cultivation-independent techniques have been revealed to be very useful for the analysis of microbial diversity, as they are more reproducible and are free of the common biases derived from the traditional cultivation-based methods. In the recent years, the denaturing gradient gel electrophoresis (DGGE) technique has been successfully applied to explore the diversity of microbial communities and changes in microbial populations when exposed to fluctuations of environmental conditions (El Frantoussi et al. 1999; Luxmy et al. 2000).

In this study, the biological treatment of a synthetic aqueous stream containing FB was investigated in an upflow fixed bed reactor (UFBR) using GAC as the growth support matrix, when exposed to variable operating conditions, namely, transient concentrations of the pollutant and temporary suspension of substrate feeding. Given the uncommon capacity of strain F11 to completely degrade $\mathrm{FB}$, the UFBR was inoculated with a pure culture of this strain in order to evaluate its biodegradation performance and its stability in such bioreactor system. The dynamics of the bacterial community developed along the UFBR operation was also a target of this investigation. To our knowledge, this is the first study reporting the biological treatment of FB in a GAC bioreactor inoculated with a microorganism capable of growing on this compound as a sole carbon and energy source.

\section{Materials and methods}

Bacterial inoculum A single bacterial strain capable of growing on FB as a sole carbon and energy source was used to set up the bioreactor. Strain F11 was isolated from a consortium previously enriched from a chemically contaminated site in northern Portugal (Carvalho et al. 2005). Pure cultures of F11 were grown in sealed flasks containing a minimal salts liquid medium (MM) (Caldeira et al. 1999) supplied with $100 \mathrm{mg} \mathrm{l}^{-1}$ of FB. The flasks were closed with gas-tight rubber stoppers coated with a Teflon layer. Cultures were started in $100-\mathrm{ml}$ flasks, filled to one-fifth of their volume, and progressively increased by sequentially transferring the cultures to $500-\mathrm{ml}$ and $1,000-\mathrm{ml}$ flasks filled to one-third of their volumes. The flasks were incubated on a rotatory shaker at $150 \mathrm{rpm}$ and $25^{\circ} \mathrm{C}$. Growth was monitored at $600 \mathrm{~nm}$, and FB biodegradation was followed through the measurement of fluoride ion liberation.

Reactor design and operation A continuous UFBR was operated for treating an FB-containing aqueous stream. The reactor consisted of a cylindrical stainless steel column (33 cm height and $3 \mathrm{~cm}$ internal diameter) provided with sampling ports at its entrance, exit, and middle points (Fig. 1). The column was packed with $45 \mathrm{~g}$ of dry weight GAC (0.85-2.4 mm particle size), with an empty bed volume of $184 \mathrm{~cm}^{3}$ ( $80 \%$ of reactor volume). Prior to use, GAC was washed several times with deionized water to remove carbon fines, dried in an oven at $105^{\circ} \mathrm{C}$, and sterilized by autoclaving.

A silicon membrane, permeable to oxygen and pressurized with filtered air, was introduced inside the reactor to provide additional oxygen for FB degradation, whilst preventing evaporative losses of the compound. The membrane was folded in a helicoidal form around an inert metal support and placed in the center of the reactor. The total membrane area available for oxygen diffusion was $180 \mathrm{~cm}^{2}$. GAC was packed inside the reactor such that the membrane support was completely covered by this matrix. The GAC column was inoculated with $200 \mathrm{ml}$ of an F11 culture with a biomass concentration of $119 \mathrm{mg} \mathrm{l}^{-1}$. The purity of the inoculum was checked by spreading diluted suspensions of the F11 culture onto nutrient agar (NA) plates. The inoculum was recirculated through the packed column for 3.5 days at a flow rate of $10 \mathrm{ml} \mathrm{h}^{-1}$ to allow colonization of the support material. The decrease $(>90 \%)$ in the optical

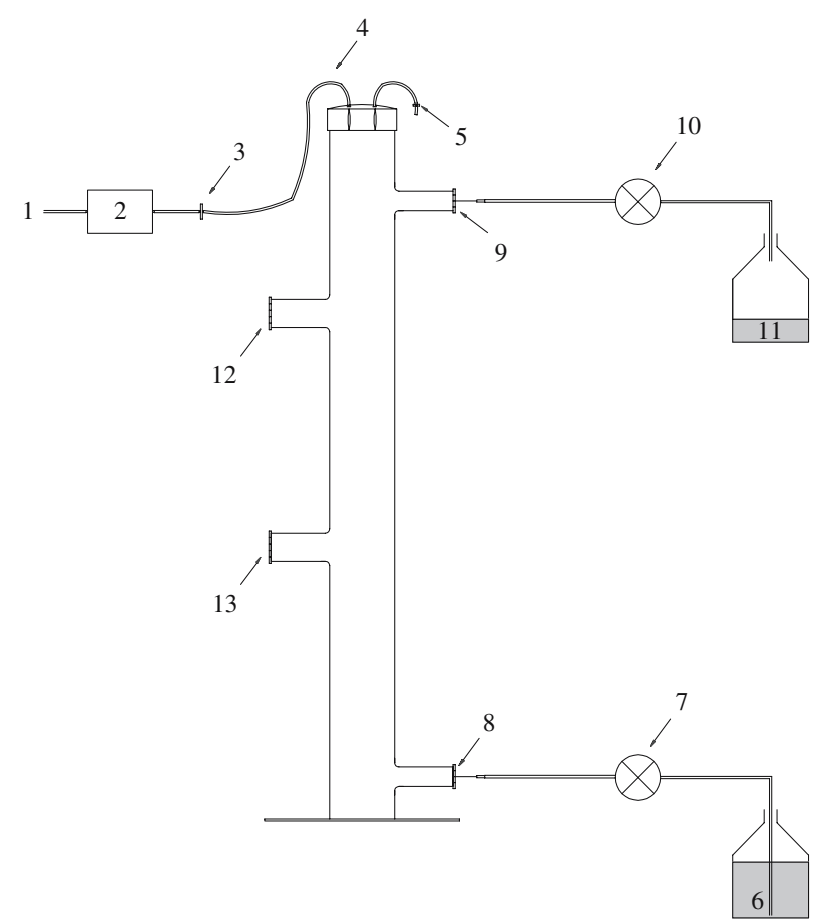

Fig. 1 Schematic diagram of the continuous UFBR: 1 pressurized air, 2 air flow controller, 3 air filter, 4 air pressurized silicon membrane, 5 clamp, 6 mineral salts medium supplemented with FB, 7 and 10 peristaltic pumps, 8 inlet, 9 outlet, 11 waste, 12 top GAC sampling point, 13 bottom GAC sampling point 
Fig. 2 Degradation of FB in the continuous UFBR operated under different concentrations of FB. FB inlet concentration $(\bullet)$, FB outlet concentration (O), and FB degraded based on fluoride release $(\Delta)$ are indicated

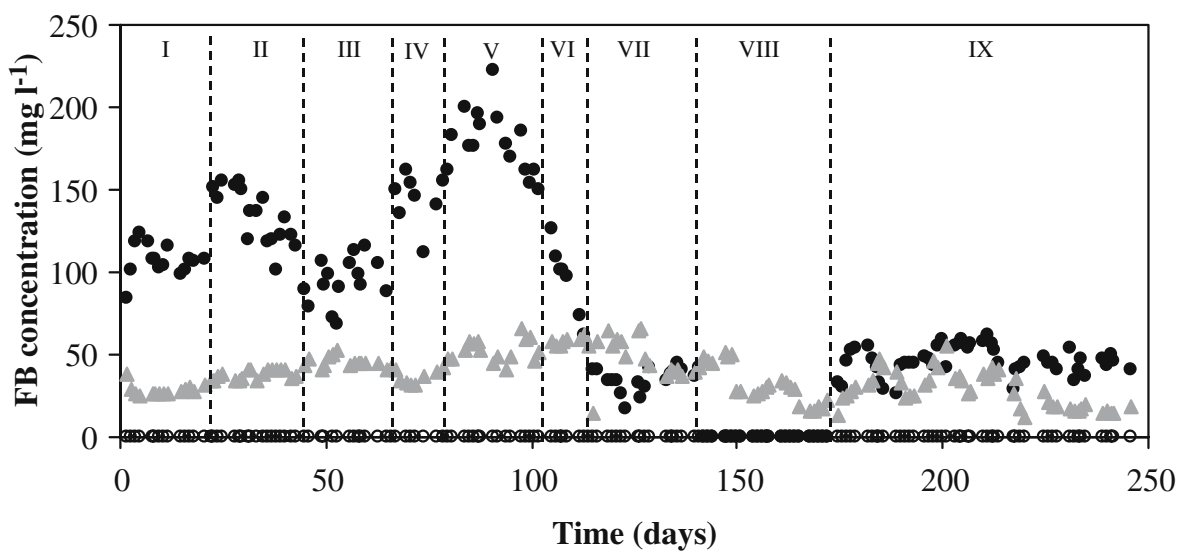

density of the recirculating inoculum was used as an indication of biomass loading onto the GAC. The UFBR was thereafter operated continuously, under no aseptic condition, at room temperature and $\mathrm{pH} 7$, and was fed with a synthetic aqueous stream consisting of $\mathrm{MM}$ and different concentrations of FB.

Sampling and analyses Liquid samples were routinely collected at the inlet and outlet of the UFBR (Fig. 1) for analysis of FB and the respective biodegradation product, fluoride. For quantification of FB losses through vaporization, gas samples were collected from the reactor headspace with a gas-tight syringe and immediately analyzed on GC by injection of $0.5 \mathrm{ml}$. Dissolved oxygen was weekly monitored in the reactor liquid outlet with an oxygen probe (WTW, Germany).

FB was analyzed by gas chromatography as described by Carvalho et al. (2005). The concentration of fluoride ions in the culture supernatant was measured, after centrifuging the samples, with an ion-selective combination electrode (model CH-8902, Mettler-Toledo GmbH, Urdorf, Switzerland), which was calibrated with $\mathrm{NaF}(0.1-10 \mathrm{mM})$ in MM.

Biofilm microbial community analysis (1) Biofilm sampling: GAC samples (1 g of wet weight) were collected from two sampling points of the bioreactor $(11$ and $21 \mathrm{~cm}$ from the bottom, Fig. 1). For extraction of biomass from the carrier surface, GAC samples were dispersed in $10 \mathrm{ml}$ of $\mathrm{NaCl}$ solution $\left(8.5 \mathrm{~g} \mathrm{l}^{-1}\right)$ and vortexed for $30 \mathrm{~s}$ at maximum speed. The resulting suspensions were used for plate counts and DGGE analyses. Effluent samples $(1 \mathrm{ml})$ were collected at the outlet of the bioreactor for bacterial enumeration through plate-count analysis. (2) Plate counts: Bacteria were enumerated by plating onto NA, in duplicate, serial dilutions of samples in $\mathrm{NaCl}$ solution $\left(8.5 \mathrm{~g} \mathrm{l}^{-1}\right)$. The plates were incubated at $25^{\circ} \mathrm{C}$ for 3 days. (3) DNA extraction: Prior to DNA extraction, approximately $8.5 \mathrm{ml}$ of the bacterial suspensions detached from GAC were centrifuged and washed twice with sterile deionized water. The pellet was kept at $-20^{\circ} \mathrm{C}$ until DNA was extracted. DNA extraction was performed using the UltraClean Microbial Genomic DNA Isolation Kit (MoBio, California). (4) Polymerase chain reaction (PCR) conditions: The general eubacterial primers $341 \mathrm{~F}-\mathrm{GC}$ and $518 \mathrm{R}$, specific for the hypervariable $\mathrm{V} 3$ region of the $16 \mathrm{~S}$ rRNA gene, were used for amplification of a fragment corresponding to positions 341 to 534 of the Escherichia coli numbering (Schäfer and Muyzer 2001). A 39-bp GC clamp was attached to the 5 ' end of the forward primer in order to prevent the complete melting of the PCR products during subsequent DGGE analysis. PCR amplification was performed in a total volume of $50 \mu \mathrm{l}$; each PCR mixture contained $10 \mathrm{ng}$ of template DNA, $2.5 \mathrm{mM}$ of $\mathrm{MgCl}_{2}, 1.5 \mathrm{U}$ of Taq DNA polymerase (Fermentas, Lithuania), $250 \mu \mathrm{M}$ of each dNTP, and $50 \mu \mathrm{M}$ of each primer. PCR products were amplified with the following program: $3 \mathrm{~min}$ at $94^{\circ} \mathrm{C}$, followed by 10
Fig. 3 Performance of the continuous UFBR. FB OL $(\bullet)$, FB $\operatorname{BRE}(\Delta)$, and $\operatorname{FB~BEC~}(\bullet)$ are indicated

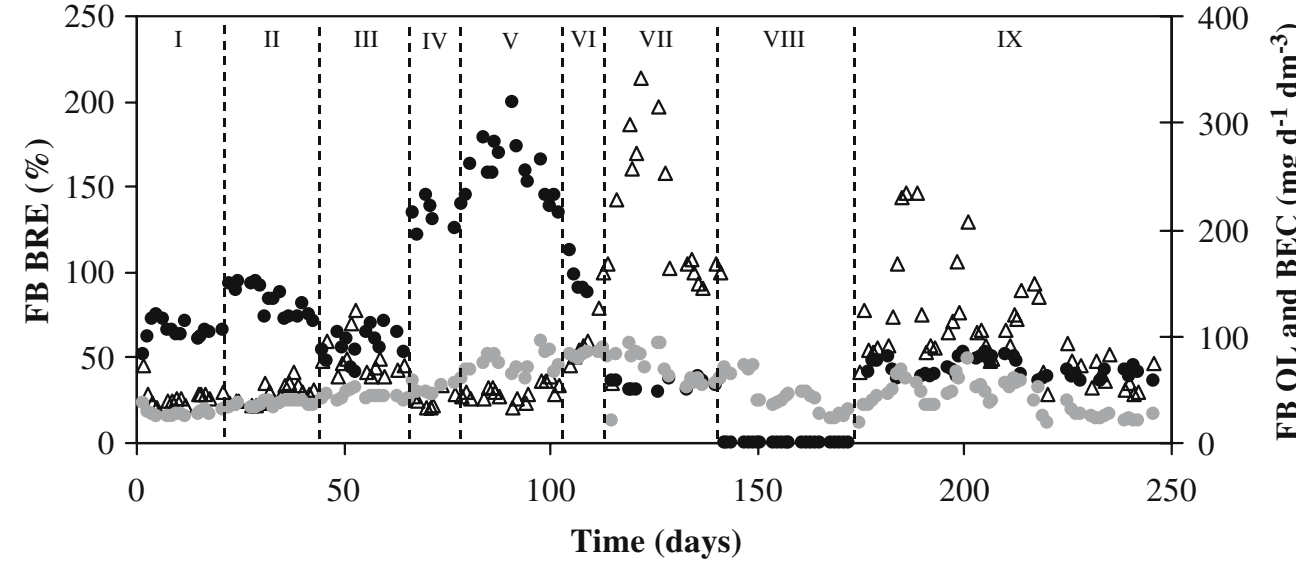


Table 1 Degradation of FB in the continuous UFBR under several operating conditions

$H R T$ Hydraulic residence time, $B R E$ biological removal efficiency, $B E C$ biological elimination capacity, $N A$ not applicable ${ }^{\mathrm{a}}$ The values listed are means \pm SEM

${ }^{\mathrm{b}}$ This phase corresponds to the no-feeding period

${ }^{\mathrm{c}}$ This value refers to the retention time of minimal salts medium, without the addition of a carbon source

\begin{tabular}{lcllllll}
\hline Phase & $\begin{array}{l}\text { Length of } \\
\text { operation (days) }\end{array}$ & $\begin{array}{l}\text { Days of } \\
\text { operation }\end{array}$ & $\begin{array}{l}\text { HRT } \\
(\mathrm{h})\end{array}$ & $\begin{array}{l}\text { Inlet } \\
\text { concentration } \\
\text { a }\left(\mathrm{mg} \mathrm{l}^{-1}\right)\end{array}$ & $\begin{array}{l}\text { Organic load } \\
\left(\mathrm{mg} \mathrm{d}^{-1} \mathrm{dm}^{-3}\right)\end{array}$ & $\mathrm{BRE}^{\mathrm{a}}(\%)$ & $\begin{array}{l}\mathrm{BEC}^{\mathrm{a}} \\
\left(\mathrm{mg} \mathrm{d}^{-1} \mathrm{dm}^{-3}\right)\end{array}$ \\
\hline I & $0-22$ & 22 & 24.5 & $107 \pm 3$ & $100 \pm 2$ & $27 \pm 2$ & $28 \pm 1$ \\
II & $23-43$ & 21 & 24.5 & $136 \pm 4$ & $130 \pm 4$ & $29 \pm 1$ & $37 \pm 1$ \\
III & $44-66$ & 23 & 24.5 & $94 \pm 4$ & $90 \pm 4$ & $49 \pm 3$ & $44 \pm 1$ \\
IV & $67-79$ & 13 & 16.7 & $149 \pm 3$ & $210 \pm 5$ & $26 \pm 2$ & $52 \pm 2$ \\
V & $80-102$ & 23 & 16.7 & $179 \pm 5$ & $260 \pm 7$ & $30 \pm 1$ & $75 \pm 2$ \\
VI & $103-114$ & 12 & 16.7 & $107 \pm 5$ & $150 \pm 7$ & $69 \pm 8$ & $83 \pm 1$ \\
VII & $115-141$ & 27 & 16.7 & $38 \pm 1$ & $60 \pm 1$ & $146 \pm 16$ & $68 \pm 4$ \\
VIII & $142-172$ & 31 & $16.7^{\mathrm{b}}$ & 0 & 0 & $\mathrm{NA}$ & $45 \pm 4$ \\
IX & $173-246$ & 74 & 16.7 & $49 \pm 1$ & $70 \pm 1$ & $65 \pm 4$ & $41 \pm 2$ \\
\hline
\end{tabular}

cycles of $30 \mathrm{~s}$ at $94^{\circ} \mathrm{C}, 30 \mathrm{~s}$ at $65-55^{\circ} \mathrm{C}$ (touchdown $-1{ }^{\circ} \mathrm{C} /$ cycle), and $30 \mathrm{~s}$ at $72^{\circ} \mathrm{C}$. Twenty additional cycles were performed: $30 \mathrm{~s}$ at $94^{\circ} \mathrm{C}, 30 \mathrm{~s}$ at $55^{\circ} \mathrm{C}$, and $30 \mathrm{~s}$ at $72^{\circ} \mathrm{C}$, followed by a final extension step of $5 \mathrm{~min}$ at $72^{\circ} \mathrm{C}$.

PCR products were purified using the NucleoSpin extract 2 in 1 Kit (Macherey-Nagel, Germany), and observed on agarose gel $(2.0 \%)$, with TAE buffer and ethidium bromide $\left(0.5 \mu \mathrm{g} \mathrm{ml}^{-1}\right)$. (5) DGGE: DGGE was carried out with a DCodeTM Universal Mutation Detection System (Bio-Rad Laboratories, Hercules, CA, USA). Samples containing approximately equal amounts $(\approx 500 \mathrm{ng})$ of the PCR products were loaded onto $8 \%(\mathrm{wt} / \mathrm{vol})$ polyacrylamide gels (37.5:1, acrylamide: bisacrylamide) in $0.5 \times$ TAE buffer (20 mM Tris-acetate, $\mathrm{pH} 7.4,10 \mathrm{mM}$ sodium acetate, $0.5 \mathrm{mM} \mathrm{Na} 2$ EDTA) using a denaturing gradient ranging from 35 to $50 \%$ (100\% denaturant contains $7 \mathrm{M}$ urea and $40 \%$ formamide). Electrophoresis was performed at $60^{\circ} \mathrm{C}$ in $1 \times \mathrm{TAE}$ buffer, initially at $20 \mathrm{~V}(15 \mathrm{~min})$ and then at $200 \mathrm{~V}(330 \mathrm{~min})$. The gels were stained with an ethidium bromide solution $(5 \mathrm{~min})$ and then rinsed in distilled water (20 $\mathrm{min})$. The image was acquired using a

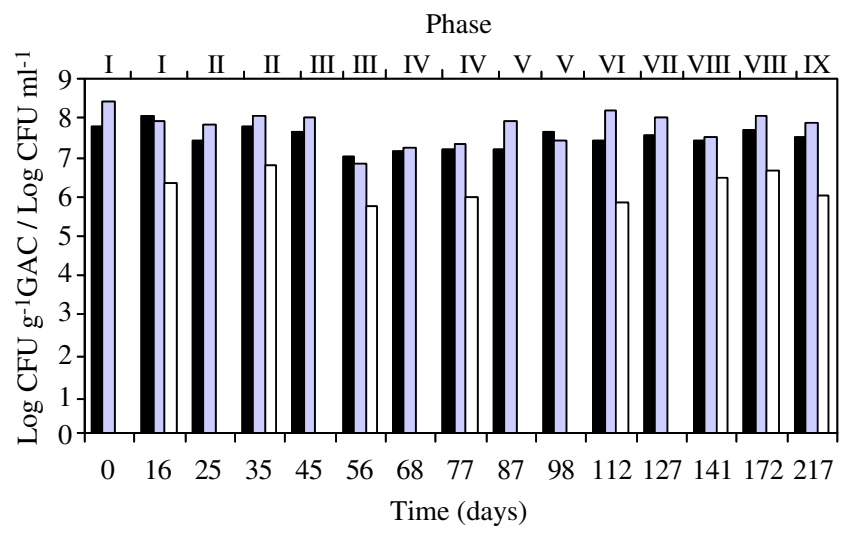

Fig. 4 UFBR microbial composition analyzed by plate counts and expressed in CFUs. GAC samples and bioreactor effluent were analyzed along the 246 days of the UFBR operation. For some sample points, effluent samples were not analyzed. The columns represent: bioreactor top sampling point $(\boldsymbol{\bullet})$, bioreactor bottom sampling point $(\square)$; bioreactor effluent $(\square)$. In the Y-axis, log CFU/g GAC is related to the bacterial counts obtained from the GAC, while $\log \mathrm{CFU} / \mathrm{ml}$ is related to the counts obtained from the bioreactor effluent
DigiDoc-IT Imaging System (Ultra-Violet Products, Ltd, Cambridge, UK). (6) Analysis of the community fingerprint: Gel images were analyzed with the Diversity Database Fingerprinting software (Bio-Rad, Richmond, CA, USA). Every gel contained one lane with a standard of eight bands to facilitate the identification of bands occupying the same position in the different lanes of the gels. A binary matrix was constructed taking into account the presence or absence of individual bands in each lane. A similarity matrix was generated using the Bray-Curtis coefficient in the PRIMER v5 software (PRIMER-E Ltd., Plymouth, UK). Dendrograms were generated using the same software, using the group average method.

Reagents All chemicals used were of the highest purity grade available (Sigma-Aldrich Chemie, Steinheim, Germany; Merck, Darmstadt, Germany). GAC (8-20 mesh) was obtained from Sigma Chemical Co., St. Louis, MO, USA.

\section{Results}

Biofilm reactor performance An UFBR was continuously operated for a period of 8 months, during which the degradation of a synthetic aqueous stream containing FB was evaluated. The parameters presented in this study to follow the biodegradation performance of the UFBR, i.e., removal efficiency and elimination capacity, were calculated and analyzed by considering only the fraction of pollutant removed by the reactor microbial biofilm. These parameters will hereafter be referred to as biological removal efficiency (BRE) and biological elimination capacity (BEC) and were calculated as defined in Eqs. 1 and 2:

$$
\begin{aligned}
& B R E=\frac{C_{F B \text { deg }}}{C_{F B i n}} \times 100 \\
& B E C=\frac{Q \times C_{F B \text { deg }}}{V}
\end{aligned}
$$

where $C_{\mathrm{FBdeg}}$ is the amount of FB degraded by the 


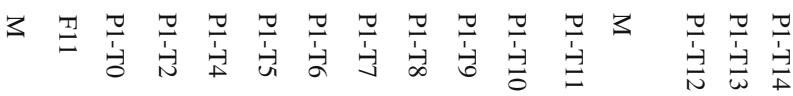

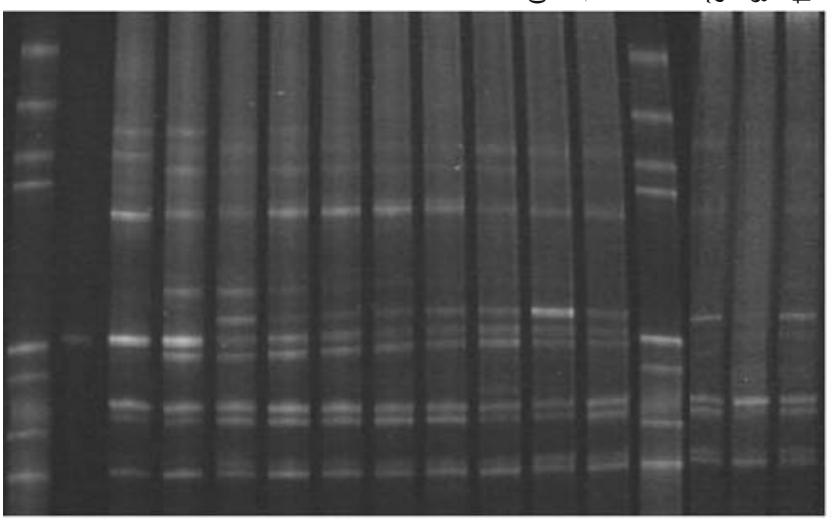

Phase

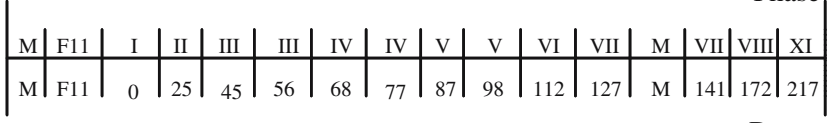

Days

a

Fig. 5 DGGE community fingerprints of the UFBR population. Gel lanes contain PCR-amplified bacterial 16S rDNA fragments from a top sampling point and b bottom sampling point, collected at different time points. $P 1$ and $P 2$ refer to reactor top and bottom sampling points, respectively. The scale under each gel figure indicates the day, and the respective phase, when the GAC was sampled from the UFBR. Lane $M$ contains a reference fingerprint,

microbial biofilm, calculated through the determination of fluoride release and expressed in concentration $\left(\mathrm{mg}^{-1}\right)$;
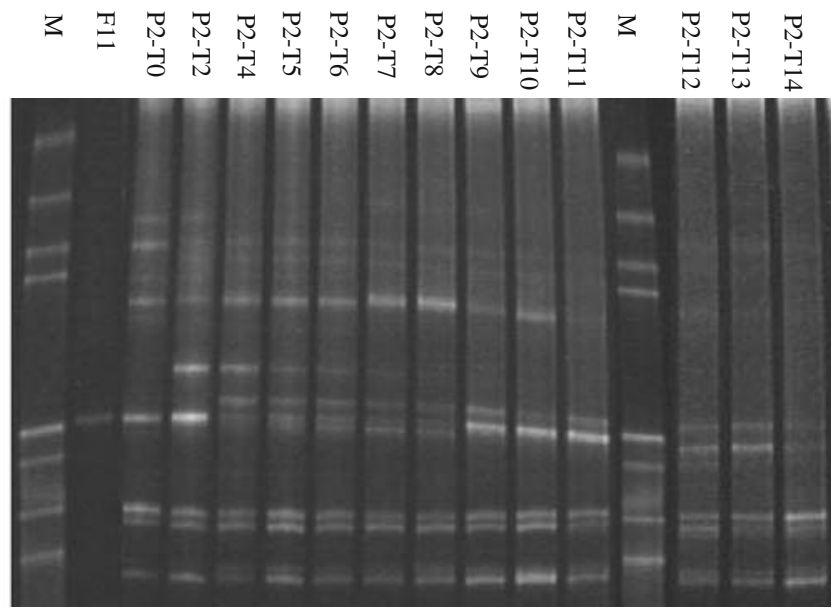

Phase

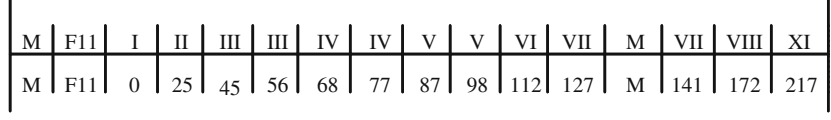

Days

b

which was constructed using previously characterized 16S rDNA clones from environmental libraries (Henriques et al. 2004) and used in this study to confirm consistent gradients of denaturants between DGGE gels and to facilitate the identification of bands occupying the same position in the different lanes of the gels. Lane F11 refers to the 16S rDNA fragment of strain F11 used to inoculate the UFBR

$C_{\mathrm{FBin}}$ represents the concentration of $\mathrm{FB}$ in the inlet aqueous stream $\left(\mathrm{mg} \mathrm{l}^{-1}\right) ; Q$ is the flow rate of the inlet
Fig. 6 Cluster analysis of the UFBR bacterial communities based upon DGGE profiles. Similarities were calculated using the Bray-Curtis measure

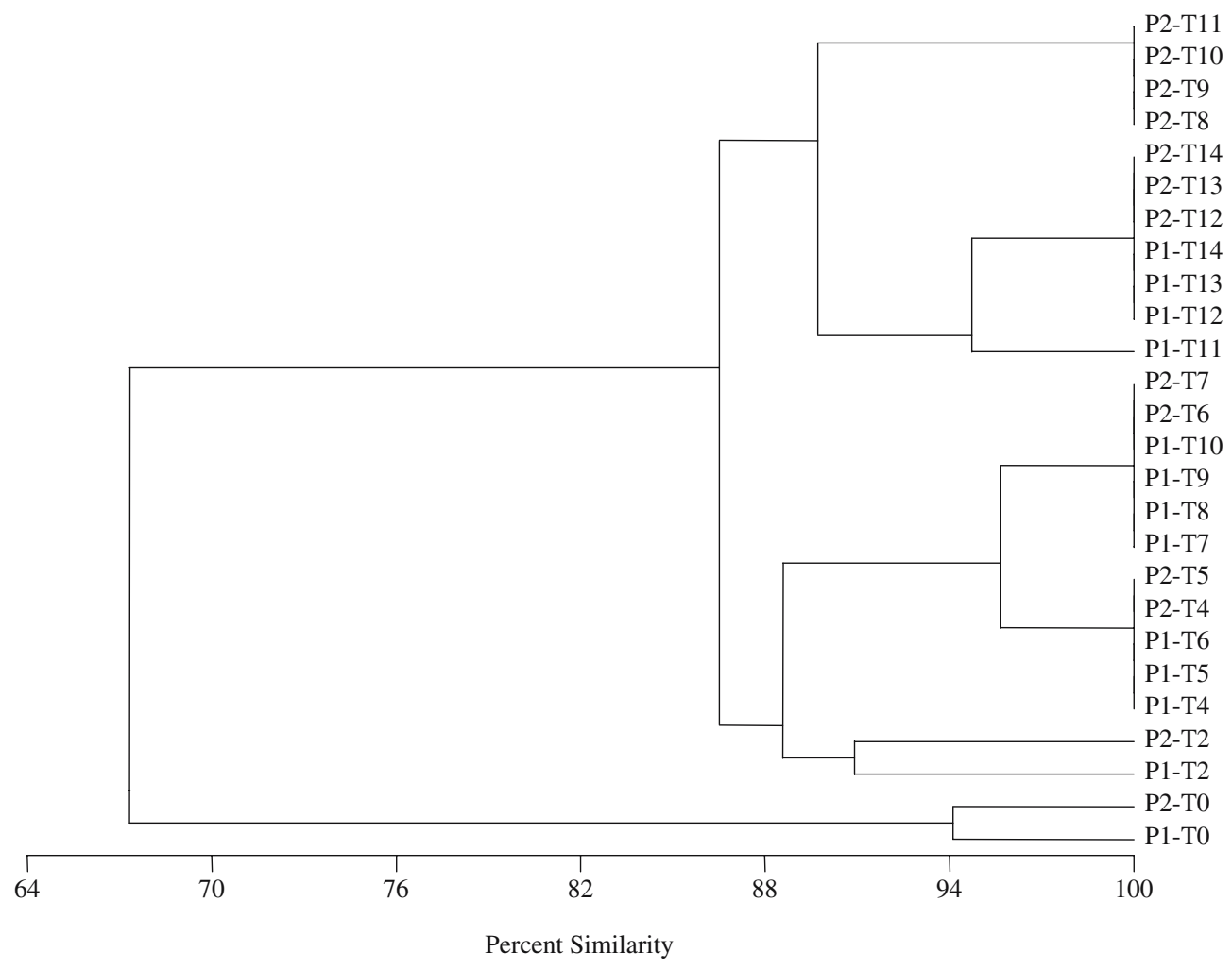

P2-T11

2-T14

2-T13

P2-T12

$\mathrm{P} 1-\mathrm{T} 12$

P1-T11

2-T6

P1-T10

P1-T8

P1-T7

2-T5

22-T4

1-T5

$1-\mathrm{T} 4$

$\mathrm{P} 1-\mathrm{T} 2$

-T0 PI-T0

Percent Similarity 
aqueous stream $\left(\mathrm{d} \mathrm{d}^{-1}\right)$; and $V$ is the working volume of the UFBR $\left(\mathrm{dm}^{3}\right)$.

The overall operational performance of the UFBR is shown in Figs. 2 and 3, and the main results obtained in each phase throughout the operation of the bioreactor are summarized in Table 1. During the first three phases (I-III), similar organic loads (OL) (between 90 and $130 \mathrm{mg}$ $\mathrm{d}^{-1} \mathrm{dm}^{-3}$ ) were fed to the UFBR, with a hydraulic residence time (HRT) of $24.5 \mathrm{~h}$. Under these circumstances, the UFBR showed a step increase in both the BRE and BEC, reaching in phase III values of $\approx 49 \%$ and $44 \mathrm{mg} \mathrm{d}^{-1}$ $\mathrm{dm}^{-3}$, respectively. From phase IV, the HRT was reduced to $16.7 \mathrm{~h}$. During phases IV to VII, a range of FB concentrations between $\approx 40$ and $180 \mathrm{mg} \mathrm{l}^{-1}$ were fed to the UFBR. Phases IV and V were characterized by a significant increase in the OL applied to the UFBR (up to $260 \mathrm{mg} \mathrm{d}^{-1} \mathrm{dm}^{-3}$ ). A decrease in the BRE was immediately observed, in spite of the continuous increase in the $\mathrm{BEC}$ to $\approx 75 \mathrm{mg} \mathrm{d}^{-1} \mathrm{dm}^{-3}$. When the OL was decreased to about $150 \mathrm{mg} \mathrm{d}^{-1} \mathrm{dm}^{-3}$ (phase VI), the BEC continued to increase and a visible improvement in the BRE was observed, achieving a value 2.3 times higher than the BRE obtained in the previous phase. In phase VII, the OL was further decreased to $\approx 60 \mathrm{mg} \mathrm{d}^{-1} \mathrm{dm}^{-3}$, and during this phase, the UFBR showed the highest BRE $(\approx 146 \%)$. A BRE value higher than $100 \%$ indicated that the biofilm was highly active, biodegrading both the FB fed in the influent and the FB previously adsorbed onto the GAC support. On day 142, feed of FB to the bioreactor was temporarily stopped (phase VIII), and during this phase, fluoride release continued to occur (Fig. 2), again indicating that the biofilm was degrading the FB adsorbed to the GAC. In phase IX, FB was reintroduced to the UFBR with an OL of $\approx 70 \mathrm{mg} \mathrm{d}^{-1} \mathrm{dm}^{-3}$, during which a BEC similar to that obtained in the previous phase (phase VIII) and a BRE of $\approx 65 \%$ were achieved, indicating that the degrading biofilm remained active after the period of substrate suspension.

The headspace of the UFBR was monitored daily to quantify for volatilization losses of FB from the system. FB was never detected in the headspace, indicating that biological degradation and adsorption to the GAC were the main removal mechanisms. Dissolved oxygen concentrations were routinely measured in the bioreactor effluent, and oxygen concentrations above $4.5 \mathrm{mg} \mathrm{l}^{-1}$ were always found, indicating that the UFBR system was not oxygen limited.

Bacterial community dynamics in the biofilm reactor

Microbial community analyses were performed along the UFBR operation. Bioreactor population was quantified through the counting of viable bacteria resultant from the GAC extraction and from the reactor effluent (Fig. 4). The biomass attached to the GAC did not suffer significant variations along time in both sampling points of the bioreactor, with the counts found for bottom sampling point being, in general, slightly higher than that for top sampling point. Significant numbers of bacterial cells were always detected in the bioreactor effluent, indicating bacterial detachment from the biofilm structure.

Bacterial suspensions extracted from GAC were also analyzed by DGGE (Fig. 5). The total number of band positions detected in the two gels was 14, and the number of DGGE bands per sample varied between 7 and 12. In general, the band patterns were quite similar along time and in the two sampling points, with slight differences being observed mainly during the start-up of the reactor operation. F11 strain was detected in all samples, although the intensity of its band in the DGGE gels varied along time. At some time points, GAC was sampled in duplicate, and the resulting bacterial suspensions were analyzed by DGGE to test the reproducibility of the results. Identical band patterns were always obtained for the analyzed duplicates (data not shown).

Cluster analysis was performed to study general patterns of community similarity among the different samples (Fig. 6). This analysis corroborates the existence of a quite stable community along bioreactor operation, with no crucial changes found between the two sampling points. At bioreactor start-up, the settled community was very similar between the two sampling points (Fig. 6, P1-T0 and P2-T0), but clearly constituted a cluster more distantly related to the samples from subsequent time points. The bacterial communities from both sampling points at T2-T7 grouped closely to one another. The T8, T9, and T10 time point samples clustered more according to time factor than with spatial distribution along the reactor, as some differences were found between the two samplings points. Samples T11-T14 exhibited no significant changes between one another.

\section{Discussion}

This work aimed at evaluating the biodegradation of FB in a UFBR packed with GAC under a continuous flow mode regime, while assessing the microbial dynamics along the bioreactor operation. A range of FB concentrations between 0 and $180 \mathrm{mg} \mathrm{l}^{-1}$ was selected for the bioreactor experiments to avoid pronounced toxic effects on microbial degradation, as previous studies conducted in batch mode with strain F11 revealed that this compound has a strong inhibitory effect on this microorganism, completely inhibiting growth at concentrations $\geq 375 \mathrm{mg} \mathrm{l}^{-1}$ (Carvalho et al. 2005). These studies also showed that strain F11 slowly degrades FB, and thus, high HRTs were chosen to operate the UFBR.

Along 246 days of UFBR operation, a total of 4,350 mg of FB was fed to the bioreactor, of which $2,190 \mathrm{mg}(\approx 50 \%)$ was biodegraded, as indicated by fluoride release. Previous GAC adsorption studies suggested that the adsorption capacity of the GAC used to pack the UFBR would not be exhausted during the whole period of bioreactor operation, thus assuring that the benefits obtained from the dual mechanism adsorption/biodegradation would be maintained until the end of bioreactor operation. 
During the first three phases of the UFBR operation, the OL applied to the reactor did not change substantially in order to allow development of the biofilm before applying higher organic loads to the bioreactor. Both BEC and BRE progressively increased during these phases, indicating a gradual adaptation of the biofilm to the operational conditions. When the OL was considerably increased during phases IV and V, a decrease in the BRE was observed, suggesting that these high organic loads applied to the UFBR, which were mainly achieved through the increasing of the FB concentration in the influent, may have caused an inhibitory effect on the microbial biofilm. As the system was buffered by the GAC adsorption capacity, this inhibitory effect was probably mainly induced in the bioreactor section closer to the influent, thus affecting mostly the microbial population resident in this area. The step decrease in the OL, applied to the UFBR during phases VI and VII, produced an improvement in the biodegradation activity, thus supporting the idea that high concentrations of FB may be inhibitory. During phase VIII, characterized by the absence of FB feeding, fluoride continued to be released, indicating that the biofilm was degrading the FB previously adsorbed onto the GAC. This result highlights the important role of GAC in bioreactor systems, in which it acts not only as a buffer by adsorbing high concentrations of the influent pollutants (Khodadoust et al. 1997; Moteleb et al. 2002), but also as a stock of the pollutant fed (Abu-Salah et al. 1996; Ivancev-Tumbas et al. 1998). When FB was not fed to the system, the biodegradation activity observed in the UFBR indicated that the adsorbed FB became bioavailable. In addition, it was demonstrated that bioregeneration of the matrix surface is feasible, contributing to extending the bed life of the adsorption matrix. The occurrence of bioregeneration in biologically activated carbon systems has been shown in studies with other pollutants (Speitel et al. 1989; Shi et al. 1995; Jonge et al. 1996; Caldeira et al. 1999).

The biofilm survival and, especially, its activity maintenance under non-operating conditions constitute a very important feature in biotreatment processes, as periods of substrate absence are a common scenario found in industry, resulting from interruptions of the industrial process leading to periods with no effluents to be treated. Immobilized reactors represent a good strategy to obviate this problem, and some studies report the capacity of such reactors to deal with this scenario (Hekmat et al. 1997; Sun and Wood 1997; Carvalho et al. 2001; Nandy and Kaul 2001). In this study, the presence of GAC in the UFBR guaranteed the continuous supply of FB to the microbial biofilm when the substrate feeding was temporarily stopped, thus preventing the microorganisms from suffering from absence of substrate. Thus, from a microbial point of view, the feeding of FB to the UFBR was always continuous, and this allowed the bioreactor to face the reestablishment of the FB feeding in phase IX as a continuous process rather than as a start-up process.

Reactor performance and community structure are two important components in a biodegradation process. In this study, the composition of the bacterial communities was analyzed both by plate counting and DGGE. No significant differences in bacterial counts along bioreactor operation were found. Slightly higher numbers of colony-forming units (CFUs) were frequently found in the samples collected from the bottom of the bioreactor, which can be due to the fact that this point is located closer to the influent. DGGE analysis provided data on the microbial diversity within the UFBR system. The major shift in the microbial community structure was observed during the start-up of the reactor. Time point $\mathrm{T} 0$, which corresponds to the analysis of GAC after inoculum adsorption and before the beginning of bioreactor operation, revealed the presence of eight and nine different bands in the top and bottom sampling points, respectively, indicating colonization of bacteria other than the original inoculum. This colonization occurred, most probably, throughout the UFBR inoculation period, during which an F11 culture was recirculated under nonsterile conditions to allow for the biofilm establishment. The occurrence of bacteria other than the inoculum fed initially to the UFBR suggests that these bacteria were able to tolerate the presence of FB, growing, most probably, at the expense of FB degradation intermediates. Generally, no significant differences were found between the two sampling points located at different axial positions in the UFBR. The major exceptions were found for samples taken at time points $\mathrm{T} 8, \mathrm{~T} 9$, and $\mathrm{T} 10$, which revealed some differences between the two sampling points. Time points T8 and T9 coincided with phase V of reactor operation, during which a higher FB concentration was applied to the UFBR $\left(\approx 180 \mathrm{mg} \mathrm{l}^{-1}\right)$. This may have contributed to the smaller microbial diversity observed in the bottom sample point, as a result of a more pronounced FB toxicity effect experienced in this reactor axial position. A similar scenario was found when the FB concentration in the feed was lowered to about $107 \mathrm{mg} \mathrm{l}^{-1}$, which corresponded to time point T10. In general, the DGGE analysis of the UFBR along time showed a quite stable microbial community, a result that has also been reported by several authors during the treatment of other aromatic compounds such as styrene and mixtures of benzene, toluene and $p$-xylene (BTX) (Massol-Deyá et al. 1997; Tresse et al. 2002; Smith et al. 2003), although other studies show variability in microbial composition (LaPara et al. 2002; Schlötelburg et al. 2002; Casserly and Erijman 2003). In the present study, the microbial stability observed during the UFBR operation might be a result of the strong selective pressure provided by the presence of FB. Strain F11 remained in the UFBR along the overall period of the bioreactor operation, suggesting that the presence of this strain is essential for the degradation of FB. Moreover, the fact that this strain was not out-competed may indicate that the capacity to degrade FB is not easily transferred to other microorganisms.

In conclusion, through a combination of adsorption and biodegradation, the UFBR used in this study showed a capacity to degrade low-strength aqueous influents containing FB. The positive protection offered by GAC, used as a biofilm support matrix, was particularly noticed during the higher organic loading, where it acted as a buffer, and during the period of absence of substrate feeding, when the 
adsorbed FB became bioavailable. In addition, the strong selective pressure exerted by the presence of FB in the reactor might have contributed to the development of a stable biofilm population.

Acknowledgements M.F. Carvalho, R. Ferreira Jorge, and I.S. Henriques acknowledge research grants from Fundação para a Ciência e Tecnologia (FCT), Portugal (BD/21839/99, BPD/6977/2001, and SFRH/BD/5275/2001, respectively) and Fundo Social Europeu (III Quadro Comunitário de Apoio). This work was supported in part by the European Community's Human Potential Programme under contract HPRTN-CT-2002-00213 [BIOSAP]. The authors thank Pedro Moradas-Ferreira (IBMC, Porto) for his support.

\section{References}

Abu-Salah K, Shelef G, Levanon D, Armon R, Dosoretz CG (1996) Microbial degradation of aromatic and polyaromatic toxic compounds adsorbed on powdered activated carbon. J Biotechnol 51:265-272

Armenante PM (1998) Suspended-biomass and fixed-film reactors. In: Lewandowski GA, DeFilippi LJ (eds) Biological treatment of hazardous wastes. Wiley, New York, pp 1-34

Banks RE, Smart BE, Tatlow JC (1994) Organofluorine chemistry: principles and commercial applications. Plenum, New York

Caldeira M, Heald SC, Carvalho MF, Bull AT, Vasconcelos I, Castro PML (1999) 4-Chlorophenol degradation by a bacterial consortium: development of a granular activated carbon biofilm reactor. Appl Microbiol Biotechnol 52:722-729

Carvalho MF, Vasconcelos I, Bull AT, Castro PML (2001) A GAC biofilm reactor for the continuous degradation of 4-chlorophenol: treatment efficiency and microbial analysis. Appl Microbiol Biotechnol 57:419-426

Carvalho MF, Alves CCT, Ferreira MIM, De Marco P, Castro PML (2002) Isolation and initial characterization of a bacterial consortium able to mineralize fluorobenzene. Appl Environ Microbiol 68:102-105

Carvalho MF, Ferreira Jorge R, Pacheco CC, De Marco P, Castro PML (2005) Isolation and properties of a pure bacterial strain capable of fluorobenzene degradation as sole carbon and energy source. Environ Microbiol 7:294-298

Casserly C, Erijman L (2003) Molecular monitoring of microbial diversity in an UASB reactor. Biodeterior Biodegrade 52:7-12

DeFilippi LJ, Lupton S (1998) Introduction to microbiological degradation of aqueous waste and its application using a fixedfilm reactor. In: Lewandowski GA, DeFilippi LJ (eds) Biological treatment of hazardous wastes. Wiley, New York, pp 1-34

El Frantoussi S, Belkacemi M, Top EM, Mahillon J, Naveau H, Agathos SN (1999) Bioaugmentation of a soil bioreactor designed for pilot-scale anaerobic bioremediation studies. Environ Sci Technol 33:2992-3001

Feakin SJ, Blackburn E, Burns RG (1995) Inoculation of granular activated carbon in a fixed bed with s-triazine-degrading bacteria as a water treatment process. Water Res 29:819-825

Freitas dos Santos LM, Lamarca D, Gilges M, New A (1999) Biodegradation of chlorobenzene, iodobenzene and fluorobenzene: batch and continuous experiments. Trans IchemE 77:4348

Heipieper HJ, Keweloh H, Rehm HJ (1991) Influence of phenols on growth and membrane permeability of free and immobilized Escherichia coli. Appl Environ Microbiol 57:1213-1217

Hekmat D, Linn A, Stephan M, Vortmeyer D (1997) Biodegradation dynamics of aromatic compounds from waste air in a tricklebed reactor. Appl Microbiol Biotechnol 48:129-134

Henriques IS, Almeida A, Cunha A, Correia A (2004) Molecular sequence analysis of prokaryotic diversity in the middle and outer sections of the Portuguese estuary Ria de Aveiro. FEMS Microbiol Ecol 49:269-279
Ivancev-Tumbas I, Dalmacija B, Tamas Z, Karlovic E (1998) Reuse of biologically regenerated activated carbon for phenol removal. Water Res 32:1085-1094

Jonge RJ, Breure AM, van Andel JG (1996) Bioregeneration of powdered activated carbon (PAC) loaded with aromatic compounds. Water Res 30:875-882

Key BD, Howell RD, Criddle CS (1997) Fluorinated organics in the biosphere. Environ Sci Technol 31:2445-2454

Khodadoust AP, Wagner JA, Suidan MT, Brenner RC (1997) Anaerobic treatment of PCP in fluidized-bed GAC bioreactors. Water Res 31:1776-1786

Klecka GM, McDaniel SG, Wilson PS, Carpenter CL, Clarck JE, Thomas A, Spain JC (1996) Field evaluation of a granular activated carbon fluid-bed bioreactor for treatment of chlorobenzene in groundwater. Environ Prog 15:93-107

LaPara TM, Nakatsu CH, Pantea LM, Alleman JE (2002) Stability of the bacterial communities supported by a seven-stage biological process treating pharmaceutical wastewater as revealed by PCR-DGGE. Water Res 36:638-646

Lee CM, Lu CJ, Chuang MS (1994) Effects of immobilized cells on the biodegradation of chlorinated phenols. Water Sci Technol 30:87-90

Luxmy BS, Nakajima F, Yamamoto K (2000) Analysis of bacterial community in membrane-separation bioreactors by fluorescent in situ hybridization (FISH) and denaturing gradient gel electrophoresis (DGGE). Water Sci Technol 41:259-268

Massol-Deyá A, Weller R, Ríos-Hernández L, Zhou J-Z, Hichey RF, Tiedje JM (1997) Succession and convergence of biofilm communities in fixed-film reactors treating aromatic hydrocarbons in groundwater. Appl Environ Microbiol 63:270-276

Moteleb MA, Suidan MT, Kim J, Maloney SW (2002) Pertubated loading of a formaldehyde waste in an anaerobic granular activated fluidized bed reactor. Water Res 36:3775-3785

Nandy T, Kaul SN (2001) Anaerobic pre-treatment of herbal-based pharmaceutical wastewater using fixed-film reactor with recourse to energy recovery. Water Res 35:351-362

Schäfer H, Muyzer G (2001) Denaturing gradient gel electrophoresis in marine microbial ecology. Methods Microbiol 30:425-468

Schlötelburg C, von Wintzingerode C, Hauck R, von Wintzingerode F, Hegemann W, Göbel UB (2002) Microbial structure of an anaerobic bioreactor population that continuously dechlorinates 1,2-dichloropropane. FEMS Microbiol Ecol 39:229-237

Shi J, Zhao XD, Hickey RF, Voice TC (1995) Role of adsorption in granular activated carbon-fluidized bed reactors. Water Environ Res 67:302-309

Smith NR, Yu Z, Mohn WW (2003) Stability of the bacterial community in a pulp mill effluent treatment system during normal operation and a system shutdown. Water Res 37:4873-4884

Song B, Palleroni NJ, Haggblom MM (2000) Isolation and characterization of diverse halobenzoate-degrading denitrifying bacteria from soils and sediments. Appl Environ Microbiol 66:3446-3453

Speitel GE, Lu CJ, Turakhia M, Zhu XJ (1989) Biodegradation of trace concentrations of substituted phenols in granular activated carbon columns. Environ Sci Technol 23:66-74

Sun AK, Wood TK (1997) Trichloroethylene mineralization in a fixed-film bioreactor using a pure culture expressing constitutively toluene ortho-monooxygenase. Biotechnol Bioeng 55: 674-685

Tresse O, Lorrain M-J, Rho D (2002) Population dynamics of freefloating and attached bacteria in a styrene-degrading biotrickling filter analyzed by denaturing gradient gel electrophoresis. Appl Microbiol Biotechnol 59:585-590

Vargas C, Song B, Camps M, Haggblom MM (2000) Anaerobic degradation of fluorinated aromatic compounds. Appl Microbiol Biotechnol 53:342-347

Wunderwald U, Hofrichter M, Kreisel G, Fritsche W (1998) Transformation of difluorinated phenols by Penicillium frequentans Bi 7/2. Biodegradation 8:379-3851 